The puzzling mitochondrial phylogeography of the black soldier fly (Hermetia illucens), the commercially most important insect protein species

Ståhls, Gunilla

BioMed Central

2020-05-24

BMC Evolutionary Biology. 2020 May 24;20(1):60

http://hdl.handle.net/10138/315645

Downloaded from Helda, University of Helsinki institutional repository.

This is an electronic reprint of the original article.

This reprint may differ from the original in pagination and typographic detail.

Please cite the original version. 


\title{
The puzzling mitochondrial phylogeography of the black soldier fly (Hermetia illucens), the commercially most important insect protein species
}

Gunilla Ståhls $^{1 *+}$ (D), Rudolf Meier ${ }^{2+} \mathbb{B}$, Christoph Sandrock ${ }^{3+}$ (D) Martin Hauser $^{4+} \mathbb{D}$, Ljiljana Šašić Zorić ${ }^{5}$, Elina Laiho ${ }^{1}$, Andrea Aracil ${ }^{6}$, Jovana Doderović ${ }^{7}$, Rozane Badenhorst ${ }^{8}$, Phira Unadirekkul ${ }^{2}$, Nur Arina Binte Mohd Adom², Leo Wein ${ }^{9}$, Cameron Richards ${ }^{8}$, Jeffery K. Tomberlin ${ }^{10}$, Santos Rojo ${ }^{6}$, Sanja Veselić ${ }^{7}$ and Tuure Parviainen ${ }^{11}$

\begin{abstract}
Background: The black soldier fly (Diptera: Stratiomyidae, Hermetia illucens) is renowned for its bioconversion ability of organic matter, and is the worldwide most widely used source of insect protein. Despite varying extensively in morphology, it is widely assumed that all black soldier flies belong to the same species, Hermetia illucens. We here screened about 600 field-collected and cultured flies from 39 countries and six biogeographic regions to test this assumption based on data for three genes (mitochondrial COI, nuclear ITS2 \& 28S rDNA) and in order to gain insights into the phylogeography of the species.

Results: Our study reveals a surprisingly high level of intraspecific genetic diversity for the mitochondrial barcoding gene COI (divergences up to 4.9\%). This level of variability is often associated with the presence of multiple species, but tested nuclear markers (ITS2 and $28 \mathrm{~S}$ rDNA) were invariant and fly strain hybridization experiments under laboratory conditions revealed reproductive compatibility. COI haplotype diversity is not only very high in all biogeographic regions (56 distinct haplotypes in total), but also in breeding facilities and research centers from six continents (10 haplotypes: divergences up to 4.3\%). The high genetic diversity in fly-breeding facilities is mostly likely due to many independent acquisitions of cultures via sharing and/or establishing new colonies from fieldcollected flies. However, explaining some of the observed diversity in several biogeographic regions is difficult given that the origin of the species is considered to be New World (32 distinct haplotypes) and one would expect severely reduced genetic diversity in the putatively non-native populations in the remaining biogeographic regions. However, distinct, private haplotypes are known from the Australasian $(N=1)$, Oriental $(N=4)$, and the Eastern Palearctic $(N=4)$ populations. We reviewed museum specimen records and conclude that the evidence for introductions is strong for the Western Palearctic and Afrotropical regions which lack distinct, private haplotypes.

(Continued on next page)
\end{abstract}

\footnotetext{
* Correspondence: Gunilla.stahls@helsinki.fi

${ }^{\dagger}$ Gunilla Ståhls, Rudolf Meier, Christoph Sandrock, Martin Hauser contributed considerably to this work.

'Finnish Museum of Natural History Luomus, Zoology unit, University of Helsinki, PO Box 17, Fl-00014 Helsinki, Finland

Full list of author information is available at the end of the article
}

C C The Author(s). 2020 Open Access This article is licensed under a Creative Commons Attribution 4.0 International License, which permits use, sharing, adaptation, distribution and reproduction in any medium or format, as long as you give appropriate credit to the original author(s) and the source, provide a link to the Creative Commons licence, and indicate if changes were made. The images or other third party material in this article are included in the article's Creative Commons licence, unless indicated otherwise in a credit line to the material. If material is not included in the article's Creative Commons licence and your intended use is not permitted by statutory regulation or exceeds the permitted use, you will need to obtain permission directly from the copyright holder. To view a copy of this licence, visit http://creativecommons.org/licenses/by/4.0/. The Creative Commons Public Domain Dedication waiver (http://creativecommons.org/publicdomain/zero/1.0/) applies to the data made available in this article, unless otherwise stated in a credit line to the data. 
(Continued from previous page)

Conclusions: Based on the results of this paper, we urge the black soldier fly community to apply molecular characterization (genotyping) of the fly strains used in artificial fly-breeding and share these data in research publications as well as when sharing cultures. In addition, fast-evolving nuclear markers should be used to reconstruct the recent invasion history of the species.

Keywords: Black soldier fly, Hermetia illucens, mtDNA COI haplotypes, Nuclear rDNA

\section{Background}

Black Soldier Flies (BSF), Hermetia illucens (Linnaeus, 1758) (Diptera, Stratiomyidae) are large flies with brownish wings and a pair of characteristic translucent pale patches (windows) on the abdomen [1]. The larvae of this synanthropic species are very effective decomposers of an exceptionally wide range of decaying organic matter including manure, food waste, agricultural by-products, organic leachates and cadavers (including human) [2-5]. Not surprisingly, the BSF has thus emerged as the dominant source of insect protein and is now utilized at a large scale worldwide due to its ability to convert organic matter into oil- and protein-rich feed (for a recent review see [6]). Indeed, the commercial value of BSF larvae is considered so significant that several types of larvae have registered trademark names: Phoenix Worms ${ }^{\oplus}$, CalciWorms ${ }^{\oplus}$, ReptiWorms ${ }^{\mathrm{TM}}$ and CalciGrubs (see https://phoenixworm.com/) [7]. In nature, adult flies rarely feed but may occasionally imbibe water or honeydew. Therefore, the larvae need to accumulate enough protein and fat during the six larval stages in order to provision the females with sufficient resources for producing 500-1000 eggs [8] and males with sufficient energy for sperm production and mating on the wing. Commercial producers in Africa, Asia, Europe, North and South America presently rear large numbers of larvae that are used as feed in aquaculture and poultry farms $[9,10]$. Many cultures were started using the immature stages of commercially available Phoenix Worms ${ }^{\oplus}$, which have been supplied for 20 years [3]. However, the origin for many new rearing cultures is unknown. This is problematic because it is common for cultures to be shared without any prior genetic characterization (e.g. genotyping).

The native range of BSF is considered to be $\mathrm{New}$ World, from northern parts of South America to the northern-most native populations occurring in the southwestern parts of the US (at least up to $40^{\circ} \mathrm{N}$ ) [11]. However, the species is now cosmopolitan and occurs in all other tropical, as well as many subtropical and temperate regions (between $46^{\circ} \mathrm{N}$ and $40^{\circ} \mathrm{S}$ ) [11-13]. All the Old World populations are considered introduced. Indeed, numerous historical records from the late 19th and early twentieth-century document the presence of the species in the New World
[13] while the earliest records for the other regions are considerably younger. For the Afrotropical region, it is a South African record from 1915 [13] and several subsequent ones from Madagascar in the 1930s [14]. The first record for the Palaearctic region is from Malta in 1926 [15], but by the 1960s the species was known from Spain, France and Italy [12, 16]. In Asia the first confirmed records are from the 1940s (e.g., Malaysia) but there are no confirmed records from, for example, China until 1960 [13]. With regard to the Australasian region, reports of $H$. illucens specimens from Australia collected in 1915 [16, 17] have now been revealed to be erroneous because they belong to a related species ( $H$. pallidipes Hill, 1919) [18]. The oldest known specimen for the conspicuous H. illucens is thus from 1948 (in Australian National Insect Collection). According to Marshall et al. [13] many Pacific islands were colonized by $H$. illucens by the1940s. This includes Hawaii, the Solomon Islands, New Caledonia, Mariana Islands, Palau, and Guam. Overall, it is striking that many of the earliest known localities outside of the New World are on islands or close to the coast. This may indicate that worldwide trade played a major role in the passive spread of BSF [12]. For example, introduction via shipping is likely responsible for the fast spread of the species throughout the Pacific region in the 1940s (e.g., Guam and Palau) given that the species' arrival coincided with troop and supply movements during WWII.

Species with exceptionally large distributions are frequently revealed to consist of species complexes or comprise several evolutionary significant units that deserve recognition once they are studied using systematic investigation using genetic methods in order to protect their genetic integrity [19-21]. Fragmentary evidence has been emerging that BSF may be such a species. For example, a regional study of mitochondrial cytochrome c oxidase I (COI) barcode variability in South Korea [22] revealed 10 highly diverged haplotypes. If confirmed for the populations and cultures worldwide, such high genetic diversity would have considerable implications for scientific research and the commercial use of the species. For example, it took decades until genotyping revealed the presence of several species in widely used 
experimental cultures of leeches in the genus Helobdella. By the time of discovery, the lack of timely genotyping had done severe harm to the scientific literature because results had been filed under incorrect scientific names [23]. Shortly after, similar problems were discovered for a "medical device", the medicinal leech Hirudo medicinalis. Many leeches used for medical purposes were revealed to belong to species that were not approved for use [24]. Yet, BSF captive cultures used in science or by companies have not been genotyped and very little is known about the genetic diversity of the species worldwide.

We here carry out a first systematic survey across the species' current range with the aim toreconstruct the phylogeography of the target species. This is particularly challenging because the species has apparently been introduced repeatedly due to international trade in many regions over the last decades. Additional complication stem from the species' being prone to escape from rearing cultures, and the international trade by commercial breeders (e.g. providing online ordering utilized by e.g. exotic-pet keepers). We therefore here compare the genetic diversity of field-collected flies (of which some, however, could be quite recent escapees) with samples obtained from rearing cultures maintained for academic or commercial purposes. In addition to mitochondrial data, we assess the genetic diversity for two fast-evolving nuclear markers (ITS2 and a loop region of $28 \mathrm{~S}$ rDNA [25-27];. Lastly, we test whether two cultures with high genetic divergence for $\mathrm{COI}$ are reproductively compatible.

\section{Results}

\section{COI barcode dataset and analyses}

All COI barcodes were trimmed to equal lengths of 658 nt, and the dataset had no gaps. The $\mathrm{A}+\mathrm{T}$ content was $61.7 \%$, and $79 / 658(12 \%)$ nucleotide sites were variable that coded for amino-acid changes in 5 of the 219 residues $(2.3 \%)$. Our study screened $>500$ fly rearing culture samples and barcoded 75 field-collected samples. These data were complemented with 49 publically available DNA barcodes from sequence databases which represented additional haplotypes and/or geographic localities (Supplementary data Table S1). All sequences were translatable and our repeated sequencing of the same specimens (15 samples representing all colonies and field-collected samples from several localities) yielded the same sequences for the same specimens. For subsequent analyses, identical COI barcodes from rearing culture samples and field-collected samples from a given geographic location were merged to retain only single representative barcodes of each haplotype (HT). The final COI dataset used for Neighbor-Joining network tree thus comprised 138 distinct barcodes representing
56 haplotypes, while the Median-Joining haplotype network had 135 barcodes representing 51 unique haplotypes (Supplementary Table S2; three incomplete sequences and four nucleotide positions excluded due to incomplete data in the latter dataset). We registered a total of 48 new haplotypes based on barcodes for the included samples and additionally 11 haplotypes already registered in public databases. The maximum uncorrected p-distance across the full dataset was $4.9 \%$. The NJ-network tree of all COI barcodes was resolved three larger sequence clusters (Fig. 1: I-III), each comprising both cultured and wild flies, while Neotropical samples mainly grouped in one larger and one smaller sequence cluster (Fig. 1). The Median-Joining haplotype network for the dataset of field-collected flies resolved the same sequence clusters (Fig. 2a).

\section{COI haplotypes: non-cultured flies}

We barcoded field-collected flies (56 sequenced in Helsinki lab, 21 in Singapore) and added 49 barcodes from public databases (Supplementary Table S1). Field-collected flies from the Neotropics show the highest number of distinct, private haplotypes (32 out of a total of 56) mainly represented by single individuals with sequence divergences up to $3.7 \%$ among them. Several unique haplotypes were recorded for the Australasian (1 haplotype), Oriental (4) and Palaearctic (4) samples (Figs. 1; 2a). For single samples from the Afrotropical and Palaearctic regions (Benin, Ghana, Malawi and Portugal) we found a haplotype nested among the New World haplotypes (Figs. 1; 2a). Samples from La Reunion, Madagascar, and Zambia (Afrotropical) shared haplotypes with samples from the Australasian, Neotropical, Oriental and Palaearctic and regions (Fig. 1: II; Table 1). A haplotype recorded for the Australasian and Oriental regions was also found in samples from the Nearctic and Palaearctic (Fig. 1: III; Table 1).

\section{COI haplotypes: cultured flies}

We sequenced the full-length COI barcode for altogether 292 samples (276 sequenced in Helsinki lab, 16 in Singapore) and recorded ten COI haplotypes from the rearing cultures (barcodes indicated with a black triangle in Figs. 1; 2b). Two shared, distinct haplotypes were recorded for samples that can be traced back to the commercial provider of 'Phoenix worms'. These samples came from China, France, Kenya, South Africa, Spain, USA and Vietnam (Fig. 1: I; Fig. 2b). The same haplotypes were also found repeatedly in field-collected flies (of which some are probably escapees) in most of these countries (Table 1). In contrast, some commercial BSF providers in Australia rear 'local' flies with private, 


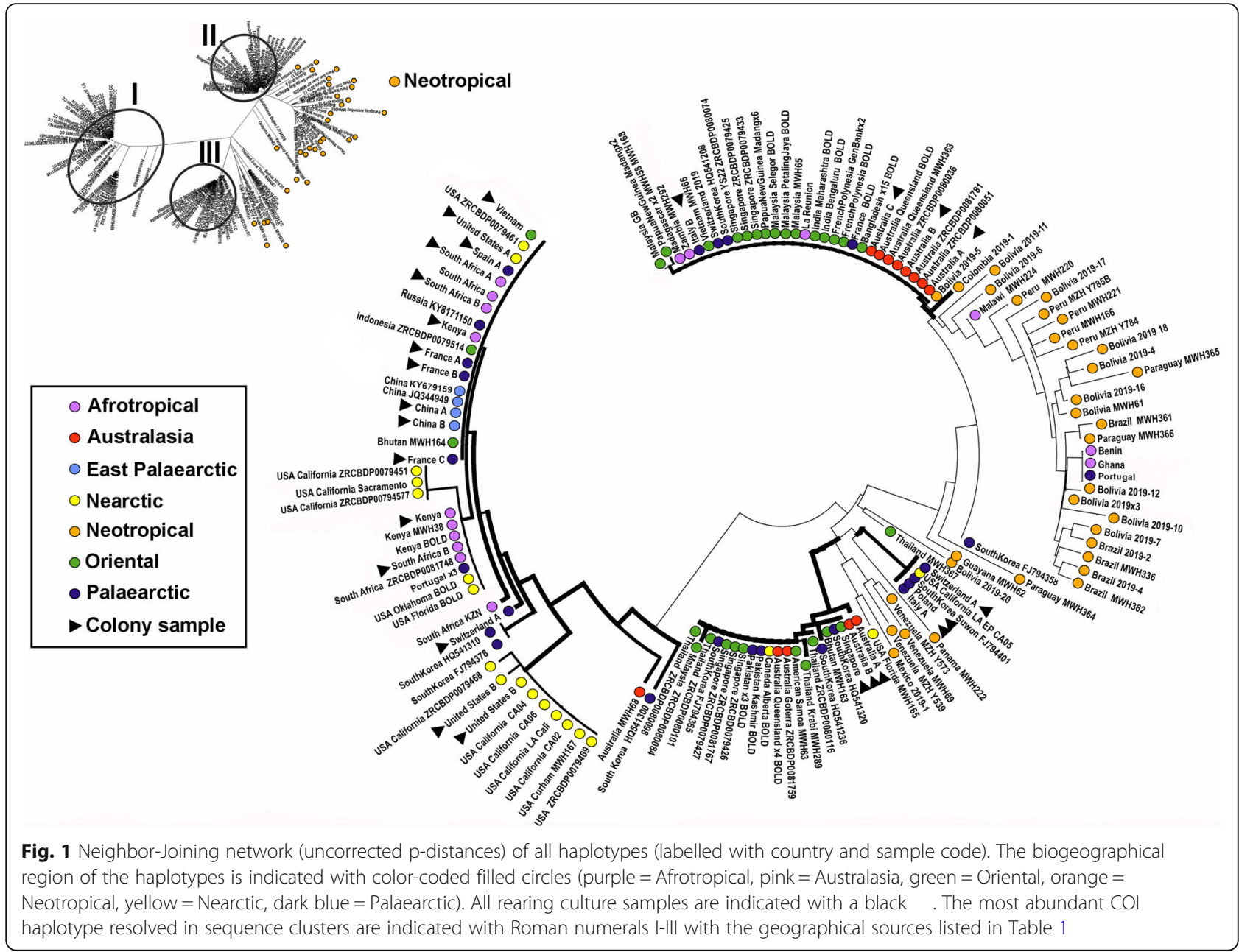

distinct haplotypes. A private haplotype was also recorded for samples from two rearing facilities in Europe (Fig. 2b), and one European rearing culture (Switzerland) had two distinct haplotypes. The most divergent rearing culture samples differed by $\mathrm{p}$ distances of up to $4.1 \%$.

\section{Nuclear ribosomal DNA}

We obtained $453 \mathrm{nt}$ of the ITS2 region for 196 samples, and only one nucleotide site was variable (some individuals were heterozygous), while all $28 \mathrm{~S}$ loop sequences were invariant.

\section{Hybridization experiments}

Mating trials under laboratory conditions revealed a lack of reproductive isolation between the populations, as hybrid offspring were produced and successfully backcrossed with the parental population. The hybrid populations were also fertile and some have now been maintained for $>10$ generations. Backcrosses were not attempted for these.

\section{Discussion}

\section{High COI barcode diversity}

Our data reveal many unexpected results for this widely used workhorse of insect protein production. They highlight that there is currently a surprising lack of background information for a species that is globally, and extensively, used and shared for scientific research, animal feed production and organic waste recycling.

Our study revealed very high COI barcode variability, but this variability is not mirrored by the two invariant nuclear markers that were included in our study. This high COI diversity also does not translate into reproductive incompatibility although the divergence levels (close to 5\%) well exceeds what is typical for flies [28]. This implies that the lack of genotyping of cultures may not have done as much scientific and commercial harm in BSF as it did for leeches belonging to Helobdella and Hirudo. The high COI diversity is structured in both expected and unexpected ways. The species is considered native to the New World; i.e., the high genetic diversity we recorded for the New World samples corresponds well with expectations, while the remaining regions 


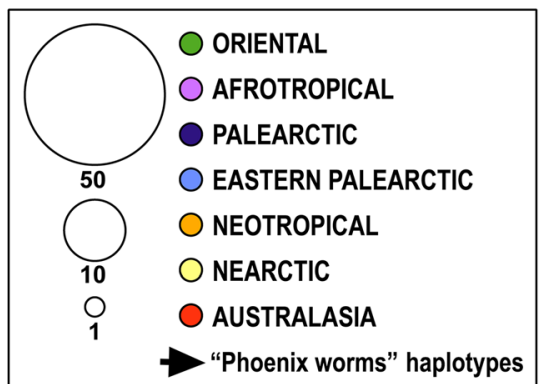

A

$$
\begin{aligned}
& \text { SOUTHA } \\
& \text { KENYA }
\end{aligned}
$$

SOUTH AFRIC
KENYA
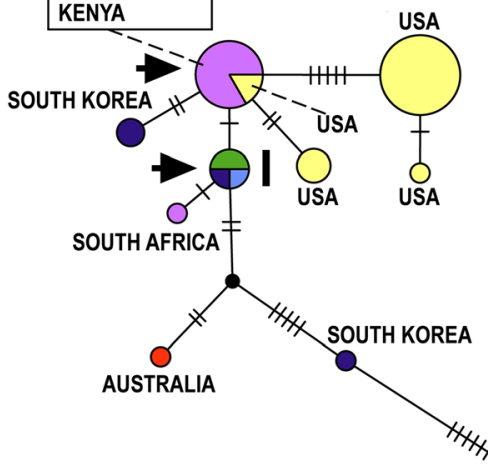

B
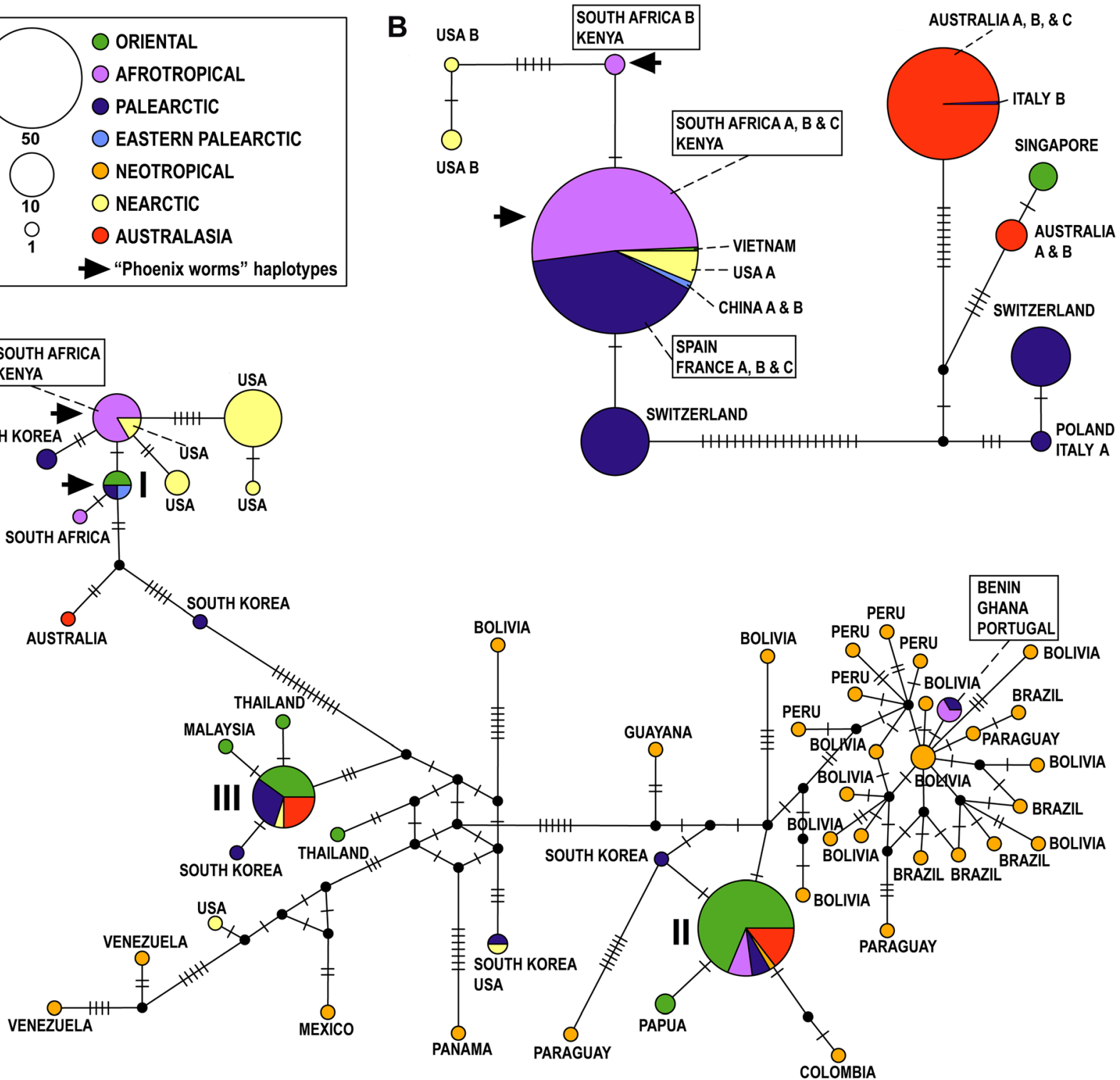

Fig. 2 a. Median-Joining haplotype network of all field-collected COI haplotypes. The black circles represent putative un-sampled haplotypes. The branch lengths are largely proportional to the numbers of mutational steps separating the haplotypes, and the number(s) of mutational steps are indicated with hashmarks on the branches. The biogeographical region of the haplotypes is color-coded, and the size of circles is proportional to the number of individuals per haplotype. The most abundant COI haplotypes are indicated with Roman numerals I-III with the geographical sources listed in Table 1. b. Median-Joining network of the ten rearing culture COI haplotypes. Descriptions as in Fig. 2a

should mostly have subsets of the New World genetic diversity. This is indeed the case for the Afrotropical and the Western Palearctic populations, which contain a limited number of haplotypes. It appears likely that these populations were indeed introduced. However, it was surprising to find several distinct, highly diverged haplotypes in Australasian, Oriental and Eastern Palaearctic populations, and this diversity remains unexplained if the species indeed originated in the New World and only recently dispersed to these regions. Possible explanations include still insufficient sampling of the
Neotropical diversity or a broader geographic origin of the species.

BSF has not only unusually high levels of genetic diversity for COI, but it is also morphologically very variable with regard to body size, wing and abdominal coloration, and the shape of translucent abdominal windows. Wing coloration varies and ranges from almost black with a blueish-metallic shine over a clear brownish-opaque insignia in the inner part of the wing to almost pale-translucent. The amount of white versus black coloration on the head shows great variation, while 
Table 1 Occurrences of partly shared haplotypes between rearing cultures and field-collected flies and resolved into three large sequence clusters (Fig. 1 I-III; Fig. 2a). In culture: Country of origin of the rearing facilities (different facilities in the same country indicated with letters A-C) of the studied BSF cultures. The total number of sequenced samples for culture samples in each country indicated in brackets. In nature: Origin of samples obtained from both pristine habitats and other natural areas (sometimes close to fly rearing facilities) with haplotypes identical to cultured flies

\begin{tabular}{lll}
\hline In culture & In nature \\
\hline I $\quad$ China: A \& B (2); France: A, B \& C (3); Kenya (17); South Africa: A, B & AFROTROPICAL: Kenya, South Africa; NEARCTIC: USA; ORIENTAL: Bhutan, \\
& \& C (57); Spain (55); Switzerland (24); USA: A \& B (9); Vietnam (1). & China, Indonesia; PALAEARCTIC: Portugal, Russia, South Korea; EASTERN \\
& PALAEARCTIC: China. \\
II $\quad$ Australia A, B \& C (65); Italy B (1). & AFROTROPICAL: La Reunion, Madagascar, Zambia; AUSTRALASIA: Australia; \\
& ORIENTAL: French Polynesia, India, Malaysia, Papua New Guinea, Singapore, \\
& Vietnam, Bangladesh; PALAEARCTIC: France, South Korea, Switzerland; \\
& NEOTROPICAL: Bolivia. \\
& AUSTRALASIA: Australia; PALAEARCTIC: Pakistan, South Korea; ORIENTAL: \\
III $\quad$ Australia A \& B (5); Singapore (4). & Singapore, Thailand, American Samoa, Bhutan, Malaysia; NEARCTIC: Canada. \\
&
\end{tabular}

the black and white pattern on the legs seem to be more consistent. There is a tendency for males to have a reddish to red abdomen, while females rarely display red coloration on the abdomen. Much of this variation can be found within the same laboratory cultures and is thus likely due to polyphenism, but more systematic study across cultures representing different haplotype groups is needed.

\section{Global trade and the distribution of BSF}

We documented that the distinct haplotypes of the commercial US breeding strain (Figs. 1 and 2 a: the haplotypes of the commercial 'Phoenix Worms' indicated with arrows) can be found in flies from natural and urban environments in the Afrotropical (South Africa, Kenya), Oriental (Bhutan, China, Indonesia) and the Palaearctic (Portugal, Russia, Spain) regions, but it cannot be ascertained whether the flies originated from (repeated) introductions or if flies are escapees from rearing cultures. Similarly, haplotypes of flies recorded in commercial and/or research cultures in Asia and Australasia are also found in field-collected flies from these and other biogeographical regions (Fig. 1: II \& III; Table 1). Barcodes of single flies sampled from Benin, Ghana, Malawi and Portugal were most similar to BSF barcodes from the Neotropical region (Figs. 1 and 2 a). These patterns are compatible with human-mediated introduction across biogeographic regions, but it will require populationlevel nuclear markers to confirm whether the introductions were sufficiently recent to be due to global trade.

Arguably, the most convincing evidence for humanmediated introductions come from specimens collected at latitudes that are unlikely to support breeding populations [13, 29-31]. The lower threshold for BSF larval survival was observed to be $15-19^{\circ} \mathrm{C}$ depending on study [32, 33], and some Canadian BSF localities are unlikely to meet this requirement. Marshall et al. [13] thus hypothesized that the annual occurrence of BSF in Ontario (Canada) is due to the disposal of unused fishing baits (larvae) by local fishermen or the accidental release of flies into nature by owners of pet reptiles. However, the evidence is not entirely conclusive because BSF flies, prepupae, and pupae are resistant to cold and can survive low temperatures $\left(5^{\circ} \mathrm{C}\right)$ for several weeks [34]. This may explain why there is an established BSF population in Northwestern Switzerland that has been regularly encountered for over a decade. In addition, wild BSF are occasionally caught in Western and Central European countries such as Germany [29] and the Czech Republic [31]. Overall, more research is needed in order to fully understand the thermal tolerance of BSF and its diapausing abilities. This and all other research needs to be based on genotyped cultures because it is likely that populations from different parts of the (native) range will differ with regard to thermal tolerance. One way or another, it appears likely that BSF will be able to increase its current range as global warming takes hold. We would suggest that urban populations will most likely spearhead the range expansion because they benefit readily available organic waste and benefit from higher temperatures in urban environments [32]. Range expansion may also be facilitated through population homogenization as more cultures are shared over long distances and escaped flies cross-breed with native or previously established non-native populations.

The BSF is now being actively domesticated worldwide [35], but the field lacks 'herdbook' keeping as a means to track the fly strains (see international Drosophila stock centers). The scientific utility for the genetic characterization and source documentation in commercial breeding of domestic livestock (e.g. pigs and cattle) is obvious, and genomics has not only proven useful for reconstructing the domestication history of the different breeds, but also for understanding the molecular mechanisms underlying traits of interest [36]. A tremendous amount of phenotypic plasticity among three different BSF strains in the ability of their larvae to reduce dry matter and 
associated nutrients in three different animal manures was demonstrated in a study by Zhou et al. [7], and additional evidence is emerging more recently [37]. Knowing the link between genes and trait has improved target-based breeding of domestic livestock [38], and it seems obvious that it can also be achieved for 'mini-livestock' like the BSF. Linked characterization of both the nuclear and mitochondrial genomes could prove useful, as the mtDNA COI barcode could provide sufficient initial and inexpensive information for avoiding, for example potential reduced fitness resulting from the hybridization of highly diverged strains.

\section{Puzzling phylogeography}

This study screened a comprehensive number of both cultured and wild caught BSF samples from six continents and 39 countries, including numerous from the putatively native New World and continents where BSF is an alien species. Our findings clearly highlight the need for additional sampling of New World populations as well as the Australasian and Oriental regions. In particular, the discovery of the haplotypes which are currently only known from Australasian and Oriental populations would strengthen the hypothesis of a New World origin of the species.

If a divergence rate of $2.3 \%$ per million years for insect mitochondrial DNA [39] were used as a guide, one would have to conclude that the most distant samples of the BSF haplotype network (Fig. 1) have been separated for $0.74-1.35$ million years. This would imply that the Oriental and Australasian wild samples (Fig. 1: II \& III) had already diverged 1.04 MY ago. These findings could either challenge the assumption of a New World origin or the spread of BSF was not human-mediated. Arguably, the strongest argument against the latter is that black soldier flies are conspicuous and should have been collected by early naturalists in Asia and Australasia if they had been present. Instead, the earliest records are from the 1940s.

\section{Conclusions}

A high genetic diversity has considerable implications for scientific research and commercial use of the species. Assessing the genetic makeup of cultures would seem a necessary fly culture management tool, considering the possible advantages of a high genetic diversity of the BSF strains coupled with different dominant characteristics that a breeding program could capitalize on. We therefore urge all commercial users and researchers to generate barcodes for their cultures given that this is low cost. The DNA and specimens should also be kept for future screening of additional nuclear markers. Based on our results, the
mtDNA COI barcode is sufficiently informative to be a first step marker for any genetic characterization of BSF strains or populations. The available genomic studies on the BSF are still limited [40, 41], but are expected to rapidly increase in near future, and are likely to yield additional markers. Finally, in order to unravel a more detailed dispersal history of the BSF, comprehensive population genetic analyses should be carried out.

\section{Methods}

Our study included both samples from cultures and the wild. For cultures, we screened multiple individuals (adult flies or larvae) from rearing facilities in Europe, Africa, Asia, Australia and United States. Field-collected ("wild") fly samples were collected in both urban and pristine habitats from Africa, Asia, Australasia, Europe, and the Americas, but it is often difficult to rule out that they are escaped flies from cultures. Our data were complemented with publicly available COI barcodes retrieved from GenBank (ncbi.nih.gov) and BOLD (boldsystems.org) (for data on BSF samples, GenBank accession codes and repositories see Supplementary Table S1).

\section{Laboratory procedures}

Helsinki lab. Cultured samples: Genomic DNA was extracted from 276 samples from four countries. About half of the thorax of an individual ethanol preserved fly, or from a small piece $(2 \times 2 \mathrm{~mm})$ of larval tissue was used for DNA extraction with the Nucleospin Tissue DNA extraction kit (Macherey-Nagel, Düren, Germany). Ready-to-Go PCR beads (GE Healthcare, Little Chalfont, UK) were used for amplification of the COI barcode using the universally conserved primer pairs LCO-1490 and HCO-2198 [42] of all samples.

Field-collected samples: Fly specimens were obtained from field collections or from the authors' conserved collections (Supplementary Table S1). Genomic DNA was extracted using 1-2 legs of each pinned fly specimen, as a least-invasive approach. The Phire ${ }^{\mathrm{ma}}$ Tissue Direct PCR Master Mix \#F-170S kit (Thermo Scientific Baltics UAB, Vilnius, Lithuania) was used for DNA extraction and PCR amplification. The DNA isolation followed the Dilution \& Storage protocol of the kit with slight modifications, and PCR amplifications of the COI barcode [43] using the mentioned primers followed the recommended PCR cycle conditions. We sequenced 51 samples from 23 countries. We additionally amplified and sequenced the fast evolving second Internal Transcribed Spacer (ITS2) of the nuclear ribosomal gene cluster of a high number of both rearing culture and field-collected samples using the primer pair ITS2a and ITS2b published by Beebe \& Saul [44]. 
PCR products were enzymatically purified using Illustra ExoStar (GE Healthcare) and the same primers were employed for subsequent bidirectional Sanger sequencing reactions. The laboratory work was done at FMNH Luomus DNA Lab (Helsinki, Finland), and sequencing at Sequencing Service Laboratory (FIMM Genomics, UH, Helsinki, Finland). The raw sequences were edited for base-calling errors and assembled using Sequencher vs 5.0 (GeneCodes, Ann Arbor, USA).

Singapore lab. We screened 259 specimens from 13 countries representing all six continents (Supplementary Table S1) by amplifying a 313-bp fragment of COI using either direct PCR (dPCR) [45] or DNA extraction with QuickExtract [46]. The use of tagged primers allowed for sequencing these fragments on HiSeq 2500 using the pipeline described in [46, 47]. Once unique haplotypes were identified based on the $313 \mathrm{bp}$ piece of COI, we carried out formal DNA extractions for specimens representing the different haplotypes. DNA was extracted using BioEr's GenePure Plus Nucleic Acid Extractor following the protocol of the MagaBio Insect Genomic DNA Purification Kit. Extracts were subjected to PCR to amplify the 658-bp fragment of COI using LCO-HCO and a fast-evolving 270 -bp fragment of $28 \mathrm{~S}$ ribosomal RNA using the following primer pair: 28S_P03_F: 5'- TTYRGGAYAC CTTYDGGAC-3' and 28S_P03_R: 5'- GGTTTC CCCTGACTTCDACCTGATCA-3'. Sequences for the full-length DNA barcode were obtained with Sanger sequencing while the data for the $28 \mathrm{~S}$ rDNA fragment were obtained via tagged amplicon sequencing following the same pipeline as the $313 \mathrm{bp}$ COI fragment (see above).

\section{Sequence analyses}

We used MEGA version 7 [48] for generating a Neighbor-Joining (NJ) tree (unrooted network) [49] for all haplotypes and localities using uncorrected pdistance values, and for computing pairwise divergences among the COI barcodes. Median-Joining haplotype networks can be useful for both conveying population structures and visualizing the similarity among haplotypes. We thus generated Median-Joining haplotype networks [50] using POPART [51] for all haplotypes of field-collected samples (Fig. 2a), and separately for BSF samples from rearing cultures (Fig. 2b), with geographic origins of members of sequence clusters I-III listed in Table 1. Additionally, for the full dataset of all complete BSF barcodes we also generated a Median-Joining network (Supplementary data Fig. S1).

\section{Hybridization experiments}

To examine the reproductive compatibility between populations of BSF with high mitochondrial gene divergence, we carried out two batches of hybridization experiments involving virgin males and females from different cultures. The first experiment involved 10 virgin females from a culture established based on wild caughtflies in Singapore with 10 virgin males obtained from Spain of US commercial origin (uncorrected COI pdistances between Spanish and Singapore flies range between 3.7-4.0\%). Virgin hybrid flies of both sexes were separated and then back-crossed to virgin flies from their parental cultures. The following reciprocal pairings

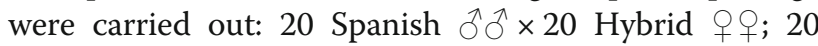
Hybrid $q 9+\times 20$ Singapore $\delta^{\lambda}$. A second batch of experiments involved $311 \mathrm{New}$ World ${ }^{\lambda} \delta^{\lambda}$ with 310 우우 from Singapore and 408 New World 9 ㅇ with 407 Singapore $\widehat{\partial} \hat{\jmath}$.

\section{Supplementary information}

Supplementary information accompanies this paper at https://doi.org/10. 1186/s12862-020-01627-2.

\begin{abstract}
Additional file 1 : Supplementary Figure S1. Median-Joining haplotype network of combined rearing culture and field-collected samples for the complete $\mathrm{COI}$ sequences. The biogeographical region of the haplotypes is color-coded, and the size of circles is proportional to the number of individuals per haplotype. The black circles represent putative unsampled haplotypes. The branch lengths are largely proportional to the numbers of mutational steps separating the haplotypes, and the number(s) of mutational steps are indicated with hashmarks on the branches. All rearing culture samples are indicated with a black. The most abundant COI haplotypes are indicated with Roman numerals I-III with the geographical sources listed in Table 1.
\end{abstract}

Additional file 2 : Supplementary Table S1. GenBank accession numbers for each distinct haplotype and locality/culture. Specimen repository indicated for pinned fly specimens (CSCA = California State Collection of Arthropods, USA; MZH = Finnish Museum of Natural History Luomus).

Additional file $\mathbf{3}$ : Supplementary Table S2. List of haplotypes.

\section{Abbreviations}

BSF: Black soldier fly; COI: Cytochrome c oxidase subunit I; HT: Haplotype; ITS2: Second Internal transcribed spacer; MY: Million years; rDNA: Ribosomal rRNA genes; WWII: World War II

\section{Acknowledgements}

We are greatly indebted to numerous museum curators and colleagues for specimen loans/donations, and we thank Elvira Rättel (Helsinki) for technical lab assistance.

\section{Authors' contributions}

$\mathrm{MH}, \mathrm{RB}, \mathrm{SR}, \mathrm{CS}, \mathrm{CR}$, and LW provided specimens. EL, AA, LSZ, JD, SV, RB, NABMA, PU and TP acquired and interpreted the data. GS, RM, CS, MH and SR conceived the study. GS, LSZ and RM analysed the data. GS, LSZ and AA prepared the figures. GS, RM, CS and MH wrote the manuscript. SR, LSZ and $J$ critically evaluated and revised manuscript versions. All authors contributed to the revising of the final version of this manuscript, approved of and agreed to be held accountable for the content therein. All authors read and approved the final manuscript.

\section{Funding}

This work was funded by the H2020 Research and Innovation Staff Exchange Programme of the European Commission (RISE), project 645636: 'Insect-plant relationships: insights into biodiversity and new applications' (FlyHigh), and the grants R-154-000-B46-114 and R-154-000-A94-592 to RM, as well as a grant of the Swiss Federal Office for Agriculture to CS ('Efficiency and 
sustainability of the production and feeding of insect based feedstuff to fish and poultry').

\section{Availability of data and materials}

The data supporting the conclusions of this article are included in the additional files of the article.

\section{Ethics approval and consent to participate}

Not applicable.

\section{Consent for publication}

Not applicable.

\section{Competing interests}

All authors declare we have no competing interests.

\section{Author details}

${ }^{1}$ Finnish Museum of Natural History Luomus, Zoology unit, University of Helsinki, PO Box 17, Fl-00014 Helsinki, Finland. ${ }^{2}$ Department of Biological Sciences, National University of Singapore, Block S3 \#05-01, 14 Science Dr 4 Singapore 117543, Singapore. ${ }^{3}$ Department of Livestock Sciences, Research Institute of Organic Agriculture (FiBL), Ackerstrasse 113, 5070 Frick, Switzerland. ${ }^{4}$ California Department of Food and Agriculture, Plant Pest Diagnostics Branch, 3294 Meadowview Road, Sacramento, California 95832-1448, USA. ${ }^{5}$ BioSense Institute, Dr Zorana Đinđića 1, Novi Sad 21000, Serbia. ${ }^{6}$ Department of Environmental Sciences \& Natural Resources, University of Alicante, PO Box 99, E-03080 Alicante, Spain. ${ }^{7}$ Department of Biology and Ecology, Faculty of Sciences, University of Novi Sad, Novi Sad 2100, Serbia. ${ }^{8}$ Agriprotein, 1 Rochester Road, Cape Town, South Africa. ${ }^{9}$ Protenga, 302 Ang Mo Kio Ave 3, \#01-1840 560302, Singapore, Singapore. ${ }^{10}$ Department of Entomology, Texas A\&M University, TAMU 2475, College Station, TX 77843-2475, USA. " VTT Technical Research Centre of Finland Ltd, TT2 Tietotie 2, P.O. Box 1000, Fl-02044 VTT Espoo, Finland.

\section{Received: 19 December 2019 Accepted: 13 May 2020} Published online: 24 May 2020

\section{References}

1. Hauser M, Woodley N, Fachin DA. Stratiomyidae. In: Kirk-Spriggs AH \& Sinclair BJ (eds.) Manual of Afrotropical Diptera. Volume 2. Nematocerous Diptera and lower Brachycera. Suricata 2017;5:919-979.

2. Lord WD, Goff ML, Adkins TR, Haskell NH. The black soldier fly Hermetia illucens (Diptera: Stratiomyidae) as a potential measure of human postmortem interval: observations and case histories. J Forensic Sci. 1994;39:215-22.

3. Sheppard DC, Tomberlin JK, Joyce JA, Kiser BC, Sumner SM. Rearing methods for the black soldier fly (Diptera: Stratiomyidae). J Med Entomol. 2002:39:695-8

4. Tomberlin JK, Sheppard DC, Joyce JA. Black soldier flies (Diptera Stratiomyidae) colonization of pig carrion in South Georgia. J Forensic Sci. 2005:50:152-3.

5. Popa R, Green TR. Using Black soldier Fly larvae for processing organic leachates. J Econ Entomol. 2012;105:374-8. https://doi.org/10.1603/EC11192.

6. Barragan-Fonseca KB, Dickel M, van Loon JJA. Nutritional value of the black soldier fly (Hermetia illucens L.) and its suitability as animal feed - a review. J Ins Food Feed. 2017;3:105-20

7. Zhou F, Tomberlin JK, Zheng LY, Yu ZN, Zhang JB. Developmental and waste reduction plasticity of three black soldier fly strains (Diptera: Stratiomyidae) raised on different livestock manures. J Med Entomol. 2013:50:1224-30.

8. Sheppard DC, Newton GL, Thompson SA, Savage S. A value added manure management system using the Black soldier Fly. Bioresour Technol. 1994;50: 275-9. https://doi.org/10.1016/0960-8524(94)90102-3.

9. FAO - Food and Agriculture Organization of the United Nations. 2013. Edible insects. Future prospects for food and feed security. In: Huis A. van, Itterbeeck J van, Klunder H, Mertens E, Halloran A, Muir G, Vantomme P, eds. Available from: http://www.fao.org/docrep/018/i3253e/i3253e00.htm. Accessed Oct 2017.

10. Belghit I, Liland N, Gjesdal P, Biancarosa I, Menchetti E, Li Y, Waagbø R, Krogdahl A, Lock E-J. Black soldier fly larvae meal can replace fish meal in diets of sea-water phase Atlantic salmon (Salmo salar). Aquaculture. 2019: 503:609-19. https://doi.org/10.1016/j.aquaculture.2018.12.032.
11. Rozkosný R. A biosystematic study of the European Stratiomyidae (Diptera). In: Spencer, K.A. (Ed.), Clitellariinae, Hermetiinae, Pachygasterinae and bibliography. Series Entomol. 1983;2:172-176.

12. Leclercq M. A propos de Hermetia illucens (Linnaeus, 1758) ("soldier fly") (Diptera: Stratiomyidae: Hermetiinae). Bull ann Soc Royale d'Entomol de Belgique. 1997;133:275-82

13. Marshall SA, Woodley NE, Hauser M. The historical spread of the Black soldier Fly, Hermetia illucens (L.) (Diptera, Stratiomyidae, Hermetiinae), and its establishment in Canada. J Ent Soc Ont. 2015;146:51-4.

14. Lindner E. Stratiomyiden von Madagaskar. Stuttg Beitr zur Naturkunde. 1966; 156:1-26.

15. Lindner E. Stratiomyiidae. In: Lindner, E. Die Fliegen der Palaearktischen region. Stuttgart; 1936; $218 \mathrm{pp}$.

16. Leclercq M. Dispersion et transport des insectes nuisibles: Hermetia illucens L. (Diptera Stratiomyidae). Bull. rech. agron. Gembloux, n. s. 1969:4:139-143.

17. Callan EM. Hermetia illucens (L.) (Dipt., Stratiomyidae), a cosmopolitan American species long established in Australia and New Zealand. Entomol. Monthly Mag. 1974;109:232-4.

18. Lessard BD, Yeates DK, Woodley NE. Revision of the Hermetiinae of Australia (Diptera: Stratiomyidae). Austral Entomol. 2019;58:122-36.

19. Moritz C. Defining 'evolutionarily significant units' for conservation. Trends Ecol Evol. 1994;9:373-5.

20. Bickford D, Lohman DJ, Sodhi NS, Ng PKL, Meier R, Winker K, Ingram KK, Das I. Cryptic species as a window on diversity and conservation. Trends Ecol Evol. 2007;22:148-55. https://doi.org/10.1016/j.tree.2006.11.004.

21. Dincă V, Lee KM, Vila R, Mutanen M. The conundrum of species delimitation: a genomic perspective on a mitogenetically super-variable butterfly. Proc $R$ Soc B. 2019;286(20191311). https://doi.org/10.1098/rspb.2019.1311.

22. Park S, Choi H, Choi J, Jeong G. Population structure of the exotic Black soldier Fly, Hermetia illucens (Diptera: Stratiomyidae) in Korea. Korean J Env Ecol. 2017;6:520-8. https://doi.org/10.13047/KJEE.2017.31.6.520.

23. Bely $A E$, Weisblat DA. Lessons from leeches: a call for DNA barcoding in the lab. Evol Dev. 2006;8:491-501.

24. Siddall ME, Trontelj P, Utevsky SY, Nkamany M, Macdonald KS III. Diverse molecular data demonstrate that commercially available medicinal leeches are not Hirudo medicinalis. Proc Royal Soc B Biol Sci. 2007:274:1481-7.

25. Kehlmaier C, Assmann T. Molecular analysis meets morphology-based systematics - A synthetic approach for Chalarinae (Insecta: Diptera: Pipunculidae). Syst Entomol. 2010;35:181-95. https://doi.org/10.1111/j.13653113.2009.00500x

26. Nedeljković Z, Ačanski J, Vujić A, Obreht D, Djan M, Ståhls G, Radenković S. Taxonomy of Chrysotoxum festivum Linnaeus, 1758 (Diptera: Syrphidae) - an integrative approach. Zool J Linnean Soc. 2013;169:84-102.

27. Sonnenberg R, Nolte AW, Tautz D. An evaluation of LSU rDNA D1-D2 sequences for their use in species identification. Front Zool. 2007:4:6. https://doi.org/10.1186/1742-9994-4-6.

28. Meier R, Zhang G, Ali F. The use of mean instead of smallest interspecific distances exaggerates the size of the "barcoding gap" and leads to misidentification. Syst Biol. 2008:57:809-13.

29. Ssymank A, Doczkal D. Hermetia illucens (Linnaeus, 1758) (Stratiomyidae), a soldierfly new to the German fauna. Studia dipterol. 2010;16:84-6.

30. De Groot M, Veenvliet P. Hermetia illucens L. (Diptera, Stratiomyidae), a new alien invasive species in Slovenia. Acta Entomol Slovenica. 2011:19:195-8.

31. Roháček J, Hora M. A northernmost European record of the alien black soldier fly Hermetia illucens (Linnaeus, 1758) (Diptera: Stratiomyidae). Čas. Slezské zemské muz. 2013;62:101-6.

32. Chia SY, Tanga CM, Khamis FM, Mohamed SA, Salifu D, Sevgan S, Fiaboe KKM, Niassy S, van Loon JJA, Dicke M, Ekesi S. Threshold temperatures and thermal requirements of black soldier fly Hermetia illucens: implications for mass production. PLoS One. 2018;13:e0206097. https://doi.org/10.1371/ journal.pone.0206097.

33. Holmes LA, Van Laerhoven SL, Tomberlin JK. Lower temperature threshold of black soldier fly (Diptera: Stratiomyidae) development. J Insects Food Feed. 2016:2:255-62

34. Spranghers T, Noyez A, Schildermans K, De Clercq P. Cold hardiness of the Black soldier Fly (Diptera: Stratiomyidae). J Econ Entomol. 2017;110:1501-7.

35. Tomberlin J, van Huis A. Black soldier fly from pest to 'crown jewel' of the insects as feed industry: an historical perspective. J Ins Food Feed. 2020;6(1): 1-4. https://doi.org/10.3920/JIFF2020.0003

36. Bosse M. A Genomics Perspective on Pig Domestication. In: Animal Domestication, Teletchea, F. (Ed.) IntechOpen, 2018. doi: https://doi.org/10. 
5772/intechopen.82646. Available from: https:/www.intechopen.com/ books/animal-domestication/a-genomics-perspective-on-pig-domestication.

37. Sandrock C, Leupi S, Wohlfahrt J, Leiber F, Kreuzer M. Genotype x environment interactions in black soldier fly larvae grown on different feed substrates. 70th annual meeting of the European Federation of Animal Science. Ghent: Wageningen Academic Publishers; 2019. p. 239.

38. Merks J, Mathur P, Knol E. New phenotypes for new breeding goals in pigs. Animal. 2012;6(04):535-43.

39. Brower AVZ. Rapid morphological radiation and convergence among races of the butterfly Heliconius erato inferred from patterns of mitochondrial DNA evolution. Proc Natl Acad Sci. 1994:91:6491-5.

40. Qi Y, Xu J, Tian X, Bai Y, Gu X. The complete mitochondrial genome of Hermetia illucens (Diptera: Stratiomyidae), Mitochondrial DNA Part B 2017; 2: 189-190, doi: https://doi.org/10.1080/23802359.2017.1307708.

41. Zhan S, Fang G, Cai M, Kou Z, Xu J, Cao Y, Bai L, Zhang Y, Jiang Y, Luo X, et al. Genomic landscape and genetic manipulation of the black soldier fly Hermetia illucens, a natural waste recycler. Cell Res. 2020;30:50-60. https:// doi.org/10.1038/s41422-019-0252-6.

42. Folmer O, Black M, Hoeh W, Lutz R, Vrijenhoek R. DNA primers for amplification of mitochondrial cytochrome c oxidase subunit I from diverse metazoan invertebrates. Mol Marine Biol Biotechn. 1994;3:294-9.

43. Hebert PDN, Ratnasingham S, de Waard JR. Barcoding animal life: cytochrome c oxidase subunit 1 divergences among closely related species. Proc R Soc B. 2003;270(Suppl 1):S96-9.

44. Beebe NW, Saul A. Discrimination of all members of the Anopheles punctulatus complex by polymerase chain reaction- restriction fragment length polymorphism analysis. Am J Trop Med Hyg. 1995;53:478-81.

45. Wong WH, Tay YC, Puniamoorthy J, Balke M, Cranston PS, Meier R. 'Direct PCR' optimization yields a rapid, cost-effective, nondestructive and efficient method for obtaining DNA barcodes without DNA extraction. Mol Ecol Res. 2014;14:1271-80.

46. Wang WY, Srivathsan A, Foo M, Yamane SK, Meier R. Sorting specimen-rich invertebrate samples with cost effective NGS barcodes: validating a reverse workflow for specimen processing. Mol. Ecol. Res. 2018;18:490-501.

47. Meier R, Wong W, Srivathsan A, Foo M. 2016. \$1 DNA barcodes for reconstructing complex phenomes and finding rare species in specimenrich samples. Cladistics. 2016;32:100-10.

48. Kumar S, Stecher G, Tamura K. MEGA7: molecular evolutionary genetics analysis version 7.0 for bigger datasets. Mol. Biol. Evol. 2016;33:1870-4.

49. Saitou N, Nei M. The neighbor-joining method: a new method for reconstructing phylogenetic trees. Mol Biol Evol. 1987;4:406-25. https://doi. org/10.1093/oxfordjournals.molbev.a04045437.

50. Bandelt HJ, Forster P, Rohl A. Median-joining networks for inferring intraspecific phylogenies. Mol Biol Evol. 1999;16:37-48.

51. Leigh J, Bryant D. POPART: full-feature software for haplotype network construction. Methods Ecol Evol. 2015;6:1110-6. https://doi.org/10.1111/ 2041-210X.12410.

\section{Publisher's Note}

Springer Nature remains neutral with regard to jurisdictional claims in published maps and institutional affiliations.

Ready to submit your research? Choose BMC and benefit from:

- fast, convenient online submission

- thorough peer review by experienced researchers in your field

- rapid publication on acceptance

- support for research data, including large and complex data types

- gold Open Access which fosters wider collaboration and increased citations

- maximum visibility for your research: over $100 \mathrm{M}$ website views per year

At $\mathrm{BMC}$, research is always in progress.

Learn more biomedcentral.com/submissions 